\title{
EPA ENERGY STAR: Tackling Growth in Home Electronics and Small Appliances
}

\author{
Marla Sanchez, Richard Brown, and Gregory Homan \\ Environmental Energy Technologies Division \\ Ernest Orlando Lawrence Berkeley National Laboratory \\ University of California \\ Berkeley, California 94720
}

November 2008

This work was supported by the U.S. Environmental Protection Agency, Climate Protection Partnerships Division, Office of Air and Radiation, under U.S. Department of Energy Contract No. DE-AC02-05CH11231. 


\section{DISCLAIMER}

This document was prepared as an account of work sponsored by the United States Government. While this document is believed to contain correct information, neither the United States Government nor any agency thereof, nor The Regents of the University of California, nor any of their employees, makes any warranty, express or implied, or assumes any legal responsibility for the accuracy, completeness, or usefulness of any information, apparatus, product, or process disclosed, or represents that its use would not infringe privately owned rights. Reference herein to any specific commercial product, process, or service by its trade name, trademark, manufacturer, or otherwise, does not necessarily constitute or imply its endorsement, recommendation, or favoring by the United States Government or any agency thereof, or The Regents of the University of California. The views and opinions of authors expressed herein do not necessarily state or reflect those of the United States Government or any agency thereof or The Regents of the University of California. 


\section{Acknowledgements}

This work was supported by the U.S. Environmental Protection Agency, Climate Protection Partnerships Division, Office of Air and Radiation, under U.S. Department of Energy Contract No. DE-AC02-05CH11231. 


\begin{abstract}
Over a decade ago, the electricity consumption associated with home electronics and other small appliances emerged onto the global energy policy landscape as one of the fastest growing residential end uses with the opportunity to deliver significant energy savings. As our knowledge of this end use matures, it is essential to step back and evaluate the degree to which energy efficiency programs have successfully realized energy savings and where savings opportunities have been missed.

For the past fifteen years, we have quantified energy, utility bill, and carbon savings for US EPA's ENERGY STAR voluntary product labeling program. In this paper, we present a unique look into the US residential program savings claimed to date for EPA's ENERGY STAR office equipment, consumer electronics, and other small household appliances as well as EPA's projected program savings over the next five years. We present a top-level discussion identifying program areas where EPA's ENERGY STAR efforts have succeeded and program areas where ENERGY STAR efforts did not successfully address underlying market factors, technology issues and/or consumer behavior. We end by presenting the magnitude of “overlooked” savings.
\end{abstract}




\section{Introduction}

Consumer electronics (CE) and miscellaneous electric (ME) products are two of the most diverse residential energy end uses. These two end uses contain a broad assortment of product types ranging from televisions and set-top boxes to dehumidifiers and waterbed heaters. In 1995, the CE and ME end uses were estimated to consume 235 TWh or $25 \%$ of U.S. residential electricity (Sanchez et al. 1998), growing to 350 TWh in 2010 or 33\% of U.S. residential electricity consumption. For over a decade, EPA ENERGY STAR has broadened its portfolio to cover CE and ME products.

\section{ENERGY STAR as a national program platform}

ENERGY STAR is a voluntary labeling program operated jointly by the Department of Energy (DOE) and the Environmental Protection Agency (EPA). DOE and EPA enter into partnerships with manufacturers and key stakeholders to promote products that meet energy efficiency and performance criteria established by the agencies. By transforming the market for high efficiency products, DOE and EPA reduce air pollution and greenhouse gases associated with the consumption of energy (McWhinney et al. 2005; Brown et al. 2002).

EPA launched the ENERGY STAR program in 1992 with computers and monitors. The early program goal was to promote energy-saving features already common in laptop computers for use in desktop computer devices and monitors. Over the next five years, EPA introduced ENERGY STAR specifications for printers, facsimile machines, copiers, scanners, and multifunction devices. EPA extended the low power mode (often called standby) strategy to encompass numerous new products including TVs/VCRs, audio/DVD, telephony, set-top boxes, and digital TV adapters. The program strategy evolved to include power supply, battery charger efficiency, total product energy consumption and on mode consumption. EPA also initiated international harmonization of ENERGY STAR specifications. Since 2000, EPA established ENERGY STAR specifications for numerous residential ME products including ceiling fans, dehumidifiers, room air cleaners, and ventilation fans.

The national ENERGY STAR platform is supported by three key federal executive orders (EO 12845, EO 13123, EO 13221), federal minimum efficiency standards (digital TV adapters, ceiling fans, dehumidifiers, external power supplies), and state/utility efforts. Table 1 lists residential CE and ME products covered by ENERGY STAR specifications including the years in which specifications were revised.

All of these policy actions have combined over the past decade to make the CE and ME end uses an important component of international, national, and state energy policy. At this stage in implementation, it is necessary to look back and evaluate how successful the ENERGY STAR approach has been at realizing energy savings for these end uses in the U.S. The remainder of the paper highlights ENERGY STAR residential CE and ME savings and evaluates program success. Our study scope focuses only on residential savings for CE and ME products. The analysis treats ENERGY STAR as a leveraged national program strategy and does not attempt to attribute savings across federal, state, and local efforts. 


\section{Residential Savings for ENERGY STAR CE and ME Products}

\section{Methodology}

The following ENERGY STAR residential CE and ME products are treated in this analysis: computers (desktops, laptops, and video games), copiers, facsimile machines, multifunction devices, monitors, printers, scanners, televisions, VCRs, audio equipment, DVDs, telephony, settop boxes (including digital TV adapters), dehumidifiers, room air cleaners, ventilation fans, ceiling fans, and battery chargers. We do not have residential-only savings for external power supplies so they are not included in this analysis (Table 1).

Table 1. Summary of ENERGY STAR Residential CE and ME products

\begin{tabular}{|l|cc|}
\hline \multirow{2}{*}{ Product types included in analysis } & \multicolumn{2}{|c|}{ Specification Effective Dates } \\
\cline { 2 - 3 } & Original & Revision \\
\hline Audio and DVD ${ }^{1,2}$ & 1999 & 2003 \\
Battery charging systems & 2006 & \\
Ceiling fans & 2002 & 2003,2006 \\
Computers & 1992 & $1995,1999,2000,2007,2009$ \\
Copiers & 1995 & $1997,1999,2007,2009$ \\
Dehumidifiers & 2001 & $2006,2007,2008$ \\
Digital TV Adapters & \\
Facsimile & 2007 & \\
Monitors & 1995 & $1995,2000,2001,2007,2009$ \\
Multifunction devices & 1992 & $1995,1998,1999,2005,2006$ \\
Printers & 1997 & $1999,2007,2009$ \\
Room air cleaners & 1993 & $1995,2000,2001,2007,2009$ \\
Scanners & 2004 & \\
Set-top boxes & \\
Telephony & 1997 & 2007,2009 \\
Televisions/VCRs ${ }^{2}$ & 2001 & $* 2005,2009$ \\
Ventilation fans & 2002 & 2004,2006 \\
Source Adaped & 1998 & $2002,2004,2005,2008$ \\
\hline
\end{tabular}

Source: Adapted from Sanchez et al. (2008)

[1] Audio includes CDs, mini-systems, audio separates, and home theater in a box

[2] DVD = digital versatile disc, TV = television, VCR = video cassette recorder

[3] Digital TV Adapters are included in analysis but counted under set-top box category

[4] Specification revisions that resulted in program suspension are indicated with an “*”

ENERGY STAR savings calculations are based on a stock accounting framework that calculates the number of ENERGY STAR units in place each year. We first segment sales of each product into non-ENERGY STAR and ENERGY STAR units. Sales of ENERGY STAR units are further divided into those that are attributable/not attributable to the program. Program savings only include ENERGY STAR unit sales attributable to the program.

In the case of office equipment, televisions, set-top boxes, battery chargers, room air cleaners, and ventilation fans, we assume that, in the absence of ENERGY STAR, product efficiencies would remain approximately the same as prior to the program. In the case of VCRs, audio 
equipment, DVDs, and telephony, we assume standby mode efficiencies would have improved over time even in the absence of an ENERGY STAR program. In the case of dehumidifiers and ceiling fans, ENERGY STAR savings are calculated from the federal minimum energy efficiency level once implemented. These assumptions are based on historic energy consumption test data when available, industry feedback, and Lawrence Berkeley National Laboratory best estimates.

This methodology represents ENERGY STAR program savings and we note that these might significantly differ from consumer savings and average market savings since the reference case baseline contains explicit assumptions about what would have happened in the absence of ENERGY STAR. A complete methodology summary is available in Sanchez et al. (2008).

\section{Results}

Our reference case baseline as well as our program/policy case is shown in Figure 1. In 1998, residential $\mathrm{CE}$ and ME products targeted by ENERGY STAR consumed $150 \mathrm{TWh}$. In the absence of an ENERGY STAR program, we project that the energy consumption of these products would have increased to 249 TWh in 2007. Our policy case shows estimated "actual" $\mathrm{CE}$ and ME end use consumption (for included products) under the ENERGY STAR program. In 2007, these products together consumed 228 TWh. From 1998-2007, ENERGY STAR cumulatively saved 108 TWh or roughly 6\% of the reference case consumption over that period. These product savings represent about one quarter of total EPA ENERGY STAR electricity savings from product labeling (both residential and commercial sectors) over that same period.

Figure 1. National consumption of CE and ME loads

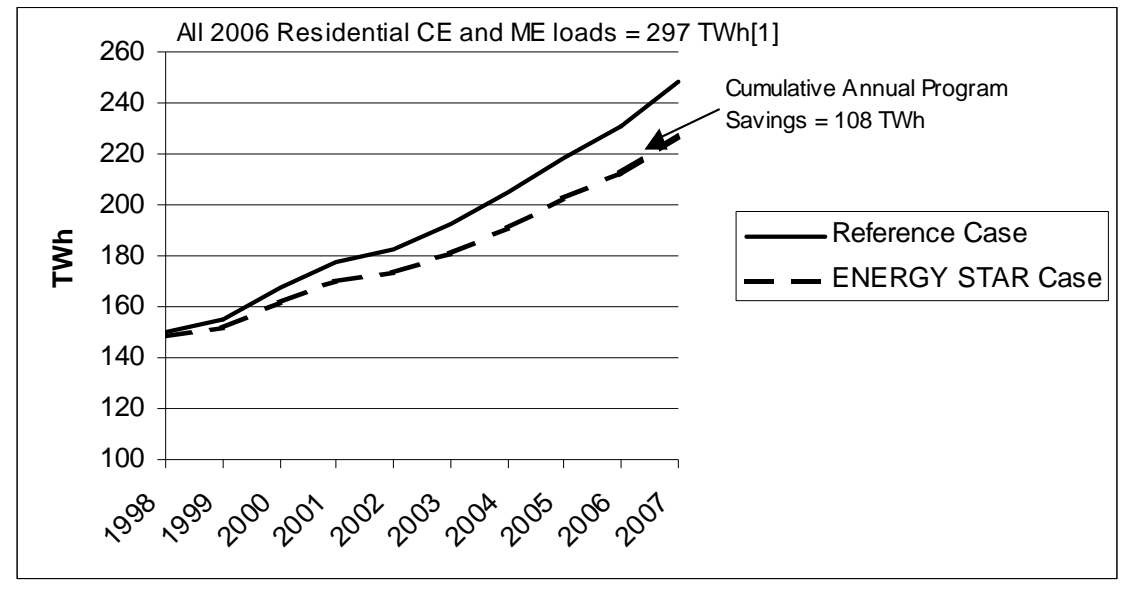

Source:

[1] Roth et al. $2007^{1}$

[2] Reference case and ENERGY STAR case from Sanchez et al. 2008

${ }^{1}$ Note that ME and CE definitions are not consistent between Roth et al. 2007 and Sanchez et al. 2008. In terms of key ME and CE, we do not consider coffee makers, security systems, outdoor and portable lighting, and microwave ovens, which are treated in the Roth study. We include dehumidifiers, room air cleaners, and ventilation fans, ceiling fan lighting which are not treated in their analysis. 
To highlight the energy savings potential of these two end uses, we have disaggregated the 2007 reference case consumption by product type (Figure 2). The miscellaneous, TV, set-top box, and computer product types account for over $80 \%$ of all reference case consumption. Although there are well over 50 million imaging equipment units installed in U.S. homes, the majority of these products are inkjet technology with lower power consumption. Similarly, although the U.S. stock of monitors is high, power consumption is moderate due to LCD technology and the success of power management. Assuming that efficiency gains are equally achievable across all product categories, the largest ENERGY STAR targets are miscellaneous products (in particular ceiling fans with lighting), TVs, set-top, and computers.

\section{Figure 2. Breakdown of Reference Case Consumption by Product Category}

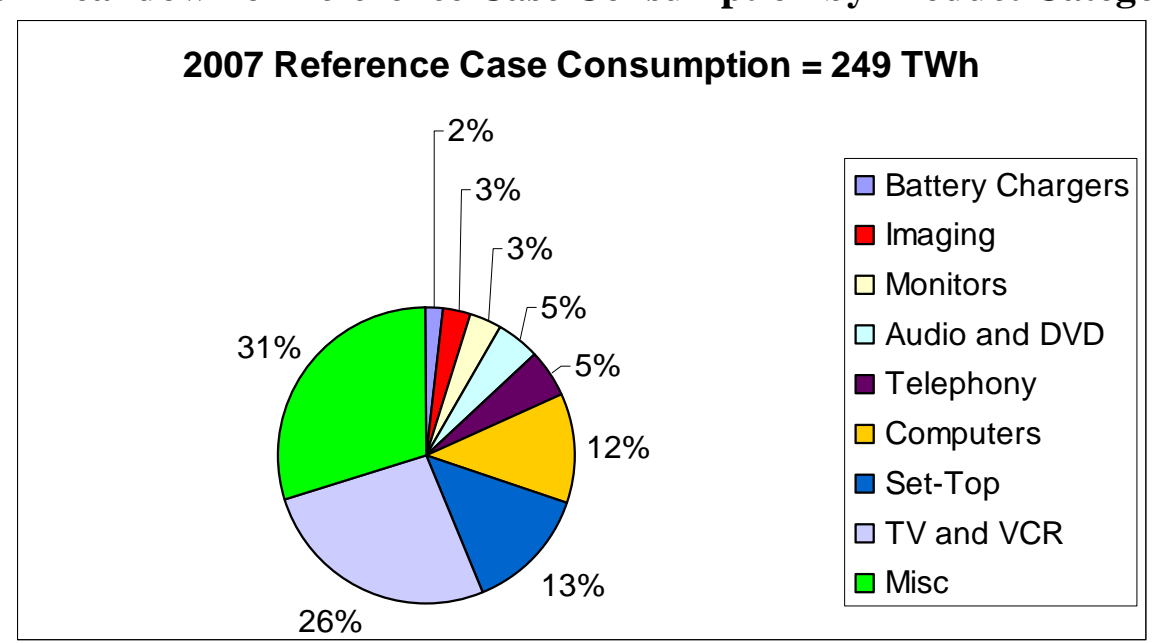

[1] Misc. includes dehumidifiers, ventilation fans, ceiling fans, and room air cleaners

[2] Computers include desktop, laptop, and video games

[3] Telephony include cordless phones, combination phones, answering machines, and additional handsets

[4] Audio includes compact audio systems, CD players, audio separates and home theater in a box

[5] Imaging includes facsimile machines, printers, scanners, and inkjet multifunction devices

Figure 3 shows how ENERGY STAR savings have actually broken out over our ten-year time frame (1998-2007) including our forecast of future savings over the next five years (2008-2012). The results show that despite being large energy targets, ENERGY STAR miscellaneous products have resulted in only $2 \%$ of total residential CE and ME savings achieved to date, computers have resulted in 8\% of total savings, and set-top boxes (discontinued in 2005 but implemented 2001-2004) have resulted in 0\% of total savings. On the other hand, ENERGY STAR televisions have been successful (41\% of CE and ME savings to date) followed by ENERGY STAR monitors ( $23 \%$ of savings to date).

Our forecasted savings fall out slightly different. The addition of ENERGY STAR on power performance levels for televisions further increases program savings (44\% of forecasted CE and ME savings). The addition of idle power requirements for ENERGY STAR computers increases savings ( $13 \%$ of our forecasted total savings). The market shift to LCD monitors actually reduces the percentage of savings attributable to ENERGY STAR monitors ( $11 \%$ of our forecasted total). The miscellaneous and set-top (set-top does not include upcoming 
specification but does include digital TV adapters) categories continue to save comparatively little energy throughout our forecast period. Projected savings from battery charging systems are insignificant to the degree that they do not register on Figure 3 even though product savings are included.

\section{Discussion}

Success in realizing savings for the largest consuming products (ME, computers, set-top boxes, and TVs/VCRs) represents one mechanism for maximizing ENERGY STAR impact within residential $\mathrm{CE}$ and $\mathrm{ME}$ end uses. Our analysis shows that a significant portion of this potential was unrealized for ME products, computers, and set-top boxes. We've identified three key factors for explaining program difficulties: participation, user behavior, and market barriers.

Figure 3. ENERGY STAR Residential CE and ME Savings (1998-2012)

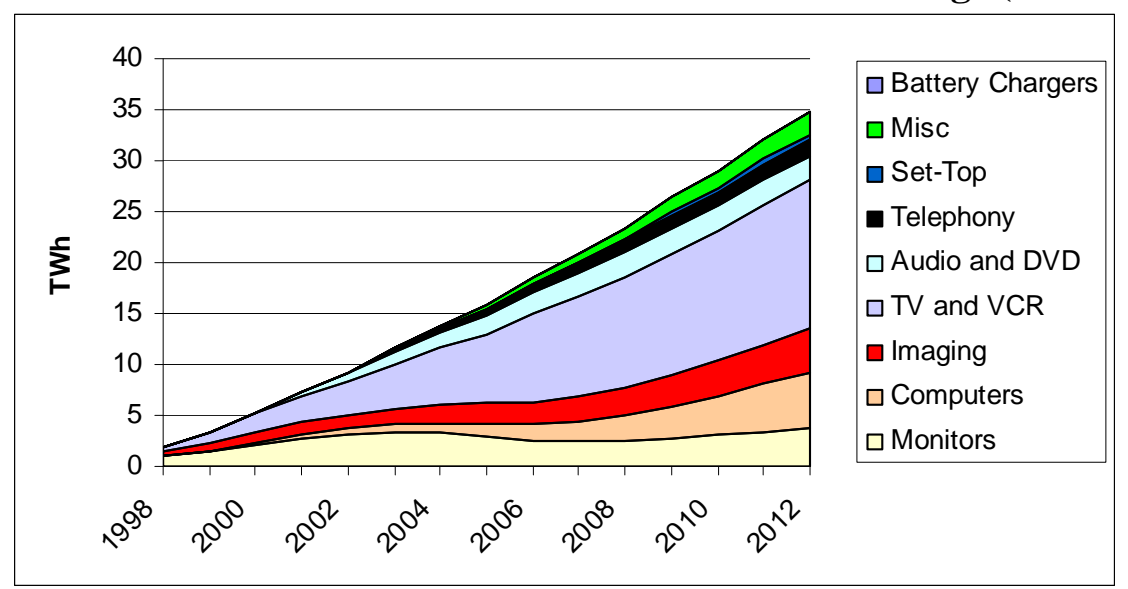

Source: Adapted from Sanchez et al. 2008

\section{Low ENERGY STAR Participation: the case of ENERGY STAR ceiling fans}

ENERGY STAR unit sales data have been collected from manufacturer partners as part of the ENERGY STAR program requirements for calendar years 2002-2006 (ICF 2003, 2004, 2006a, 2006b, 2007) ${ }^{2}$. Figure 4 shows historic and projected market penetrations for residential ME products. In the case of ME, ENERGY STAR participation rates (with the exception of dehumidifiers) are fairly low, averaging about 20\% market share across the analysis period. Of particular importance are the market penetrations for ceiling fans with lighting and ceiling fan light kits. Ceiling fans, including their lighting consumption, account for about $50 \%$ of the miscellaneous reference case consumption in 2007 (this translates into about $40 \mathrm{TWh}$ ). While the motor consumption (per unit) of ceiling fans without lights is less than $100 \mathrm{kWh} / \mathrm{yr}$, ceiling fans with integral incandescent lights or with retrofit incandescent light kits consume 300 $\mathrm{kWh} / \mathrm{yr}$ on average (Sanchez et al. 2008). As a result, the ENERGY STAR specification with CFL lighting requirements would have had a substantial impact on this end use but with a market share of less than $5 \%$, the program had little effect in reducing national consumption. market data.

${ }^{2}$ ENERGY STAR sales data for earlier years and subsequent forecast years are based on industry and 
Figure 4. ENERGY STAR Market Penetration

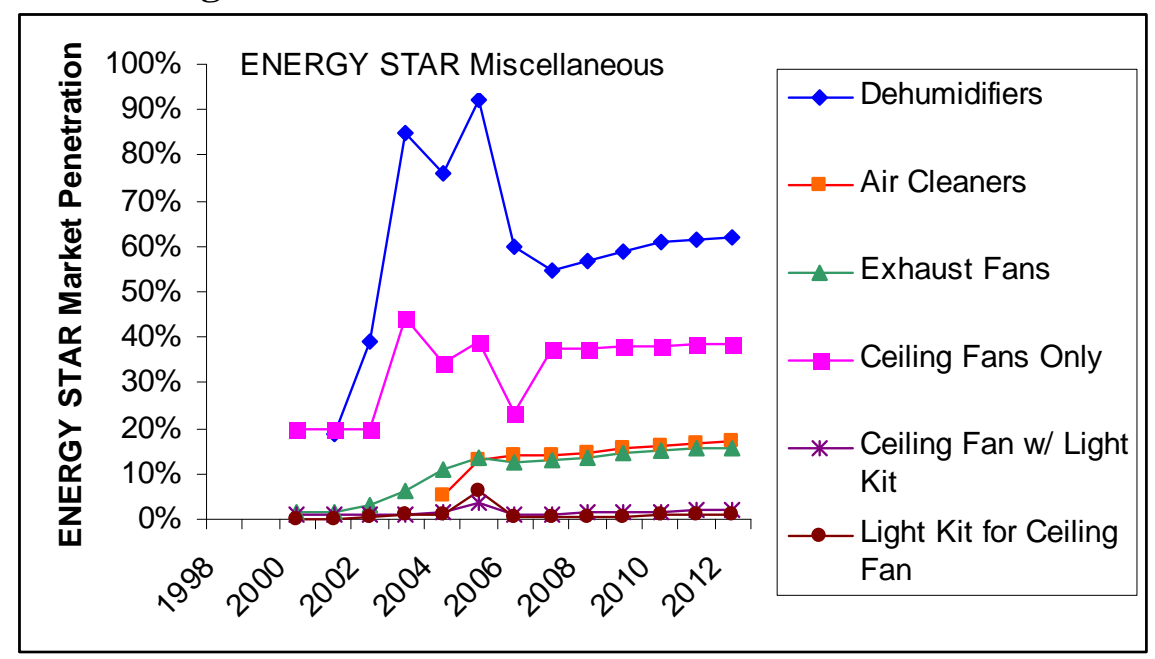

Source: ICF 2003, 2004, 2006a, 2006b, 2007

\section{User behavior: the case of ENERGY STAR computers}

Unlike ENERGY STAR ME, participation in ENERGY STAR home office products has been consistently high with market penetrations well above $90 \%$ in years preceding specification changes (1999, 2005, 2006, 2007). As noted previously, ENERGY STAR monitors as well as imaging products have been successfully achieving energy savings due to both high program participation and high power management success rates. The ENERGY STAR story is different for desktop computers. Unlike monitors and imaging equipment, desktop computers have relatively low power management success rates (20\% in homes and less than $10 \%$ in offices) due to disabling of power management or incompatibility with installed software and/or existing networks (Webber et al. 2007). While it's true that the idle power requirements in the current specification will achieve savings regardless of enabling power management, the technical potential of successfully power managing computers remains far greater.

Figure 5 illustrates this point by showing the comparative annual energy use of a desktop computer for an avid home user. While purchasing an ENERGY STAR unit results in $190 \mathrm{kWh}$ of savings (25\% reduction from standard), enabling the power management feature results in an additional $360 \mathrm{kWh}$ of savings (almost $75 \%$ reduction from a standard new unit). Successful power management will become an ever-increasing issue as networking reshapes the landscape of home electronics. Residential disabling of power management significantly reflects consumer preference, attitude and awareness. Overcoming this barrier is based as much on education as on technical solutions (perhaps even more so since home usage reflects individual preference as opposed to a network-administered office environment). For home users, education and messaging may be the most critical factor for success. 
Figure 5. Comparison of Home Desktop Energy Consumption

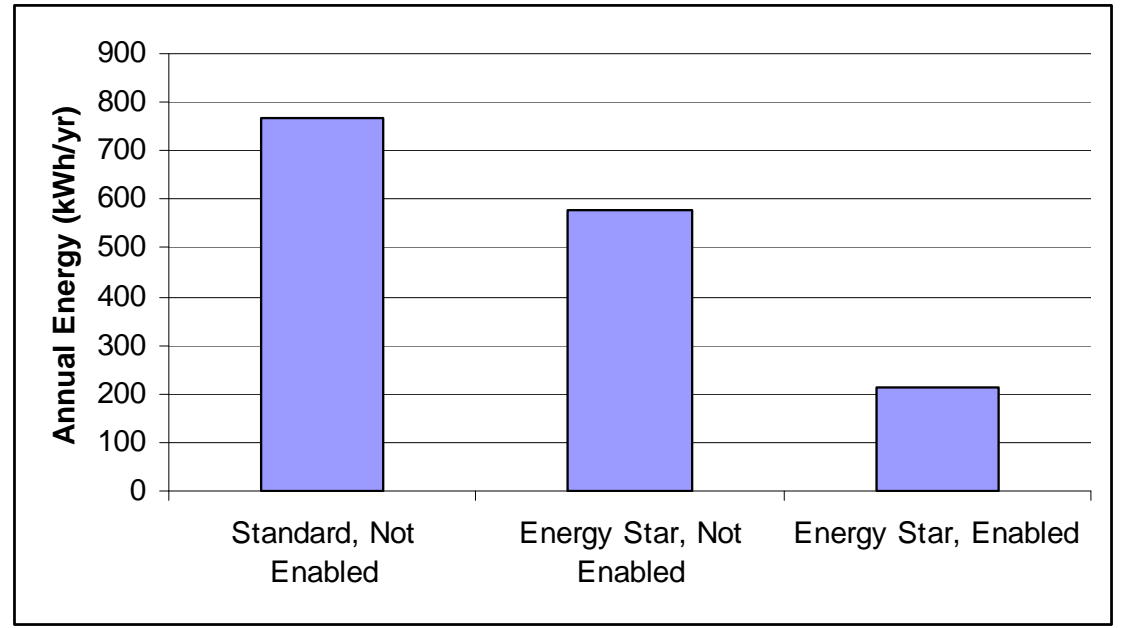

[1] All scenarios assume PC not turned off at night

[2] Not enabled assumes 3 hours active and 21 hours idle

[3] Enabled assumes 3 hours active, 3 hours idle, and 18 hours sleep

\section{Market barriers: the case of ENERGY STAR set-top boxes}

Although the ENERGY STAR specification was launched in 2001, the specification was discontinued in 2005. For the set-top box specification to be effective, there needs to be a collaborative effort between signal providers (such as Verizon and Comcast) and manufacturers who engineer the end use device. Since in many instances the boxes are not purchased by a consumer but rather rented by a consumer through a provider, it is essential that providers be "on-board" to promote the program. While the original specification did not successfully address market barriers, the new ENERGY STAR set-top box specification finalized in 2008 offers enormous potential to deliver energy savings for next generation set-top boxes. The new specification represents a combined effort of partnering with product manufacturers as well as service providers.

\section{Program success: ENERGY STAR Televisions}

Since 1998, the ENERGY STAR market share for televisions averaged around 50\% with a peak in 2004 at 90\%. Unit energy savings have also been respectable, ranging from 50 to 120 $\mathrm{kWh} /$ year under the current specification. The availability of qualifying models offered consumers a wide selection of TV models while still meaningfully differentiating the market in terms of energy efficiency. Additionally, the focus on standby power reductions easily accommodated different TV technologies (LCD, CRTs, plasma, etc.), and standby power messaging was successfully communicated to both consumers and retailers. The revised ENERGY STAR TV specification (effective in 2009) will have more of a challenge to effectively target this growing end use. The average active power of projection, LCD, and plasma TVs is 188, 176, and $383 \mathrm{~W}$ respectively (US EPA 2008a). This is considerably higher than CRT active power (75 W) ten years ago (Rosen \& Meier 1999). If addressed effectively, ENERGY STAR can achieve significant success in reducing CE energy. However, the ENERGY STAR specification that goes into effect in 2009 only reduces total TV annual 
consumption by $\sim 10 \%$ on average (US EPA 2008a). This leaves the possibility for a more aggressive target in the future, but (alone) it will likely miss the substantial savings that might have been realized as consumers purchase HD TVs in the next two years in preparation for the digital broadcast conversion.

\section{Untapped potential}

This section highlights three main targets for increasing ENERGY STAR CE and ME savings: increase residential desktop computer power management, achieve high market penetrations for ENERGY STAR set-top boxes (finalized in July 2008), and tighten energy efficiency criteria for televisions. To demonstrate the potential impact of these strategies, we analyzed three scenarios: increasing power management success rates on the stock of residential desktop computers (2009 through 2015) from the predicted $20 \%$ to $75 \%$ power management success, increase the market penetration of ENERGY set-top boxes from our predicted 25\% (for new sales 2009-2015) to $75 \%$, and reduce the on mode power consumption criteria for televisions by $20 \%$ beginning in $2009^{3}$. Together, these three strategies have the potential to increase savings by 16 TWh in 2012 and $25 \mathrm{TWh}$ in 2015. The potential is highly significant and would represent a $15 \%$ increase in all EPA ENERGY STAR electricity savings that we are currently projecting for 2015 (Table 2).

Table 2. Projected and Potential Energy Savings for Three End Use Strategies

\begin{tabular}{|l|ccc|}
\hline & $\mathbf{2 0 0 9}$ & $\mathbf{2 0 1 2}$ & $\mathbf{2 0 1 5}$ \\
\hline ENERGY STAR Desktop Computers (projected) & 3.0 & 5.4 & 8.2 \\
Increase power management to 75\% & 9.4 & 11.5 & 14.1 \\
\hline ENERGY STAR Set-top Box (projected) & 0.4 & 2.5 & 5.1 \\
Increase market penetration to 75\% & 1.3 & 7.8 & 15.7 \\
\hline ENERGY STAR TVs (projected) & 9.4 & 12.5 & 13.3 \\
Reduce on mode criteria by 20\% & 10.5 & 17.3 & 22.2 \\
\hline
\end{tabular}

Realizing these potential savings depends on the entire network of ENERGY STAR stakeholders. Consumer messaging and education (at home as well as point-of-purchase) is key to increasing residential computer power management and is likely most effectively implemented at a local level. The savings from power management messaging are real and can be accounted for, but measurement and verification of savings is a barrier to success. While usage-pattern field studies have been done in the commercial sector, and smaller statewide residential sampling has begun, no national field survey currently exists to fully support the development of a residential power management baseline (Webber et al. 2007; Porter et al. 2006).

Set-top boxes represent a concentrated market where only a handful of companies dominate the service provider industry. These companies include Comcast, Time Warner, Cox, Charter, Cable

\footnotetext{
${ }^{3}$ Note that set-top boxes were not included in the results section. Results were based on Sanchez et al. (2008), which did not include this product. The analysis reported in this section was done for U.S. EPA to specifically address the finalization of ENERGY STAR set-top boxes.
} 
Vision, Verizon, Dish, DirectTV, and AT\&T. If the majority of these providers sign-on to ENERGY STAR, the program will be successful well beyond our initial projections. If participation is low, provider incentives in local/regional utility service territories may be needed to dramatically increase program success.

Televisions offer a unique opportunity to modify our thinking about how we develop specifications for electronics products, to account for market trends toward product convergence. The general term display best defines a category of products whose primary function is to display a video signal from a video source. This broader display category consists of a base product with a video display-only functionality, as well as products with added functionality such as processing high definition audiovisual signals through an internal tuner. Implementing this broader framework allows us to treat all displays consistently (regardless of technology and end use market) and allows us to set specifications that are appropriate for the product functionality (i.e. a display with internal tuner should have a larger power allowance than a display without an internal tuner, but that allowance should only cover the actual power requirements necessary to operate the tuner).

Figure 6. On Power Consumption of Displays Tested at Factory Default Luminance

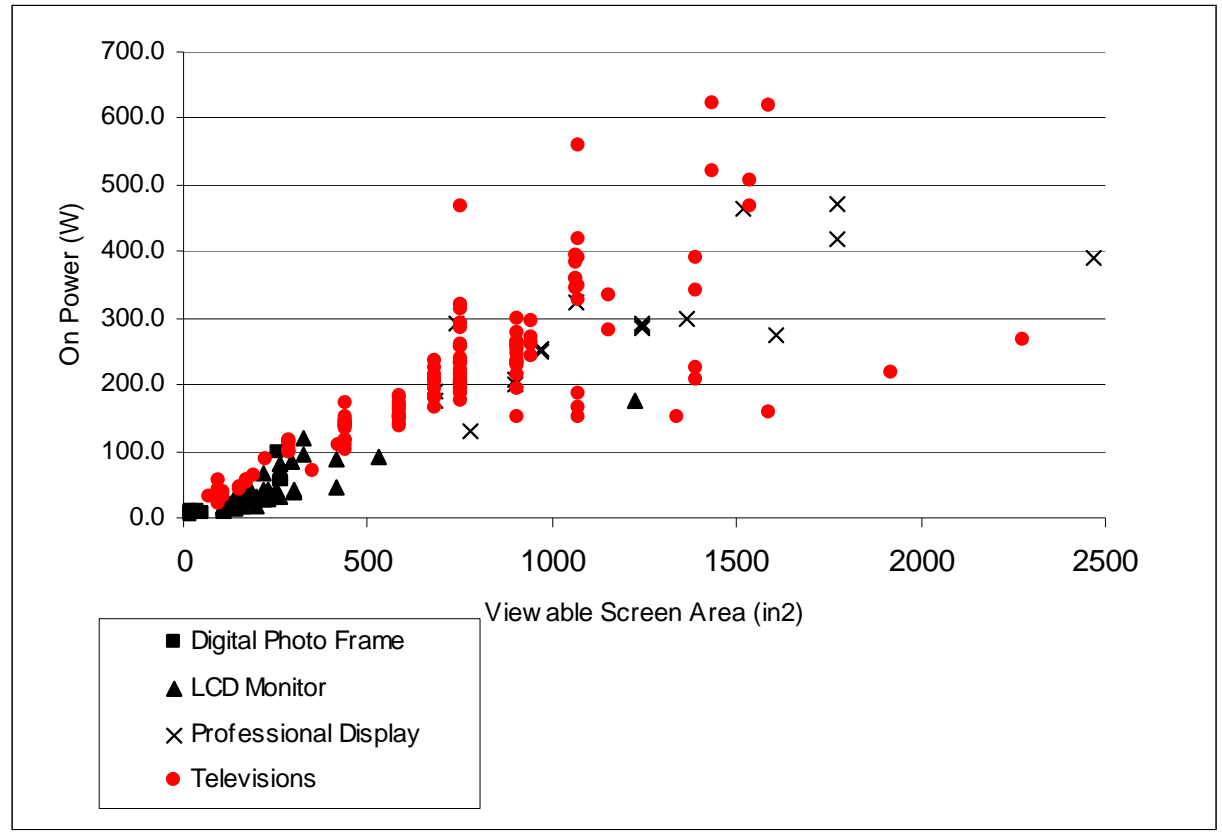

Source: US EPA 2008a, US EPA 2008b

Moving to this approach allows us to create more flexible specifications with more longevity that include existing products such as monitors and TVs, numerous new products such as digital signage and digital picture frames, and products that are likely to emerge over the next several years. This approach also allows us to consistently address display luminance, which is very likely to become an increasingly important driver of energy use, as screen sizes become larger and resolution continues to increase. On mode power consumption data for display units is available to allow us to move towards this new approach (Figure 6) along with detailed information on relevant luminance settings (Figure 7). Next steps include adapting this more 
flexible structure as we move towards a new version of ENERGY STAR “monitors" and Tier 2 ENERGY STAR TVs.

Figure 7. Factory Default Luminance Settings for Displays without Internal Tuners

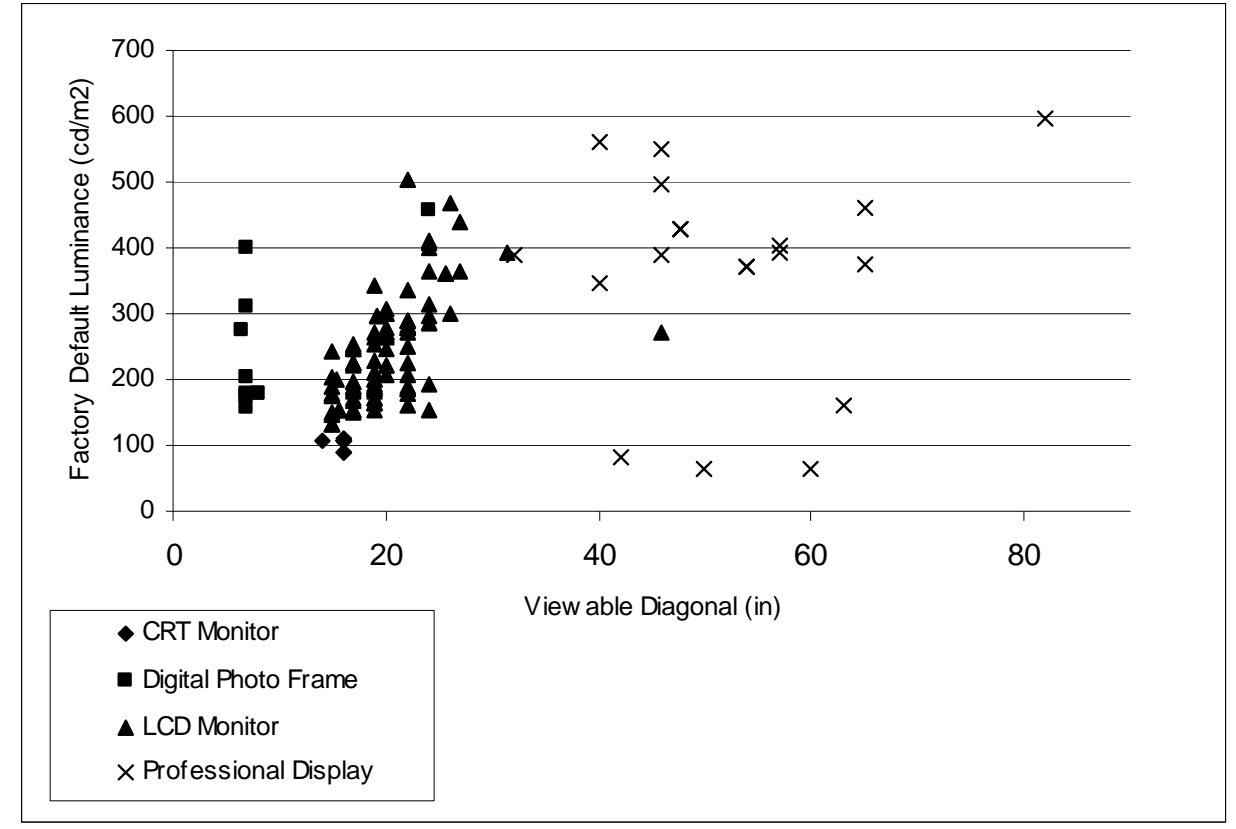

Source: US EPA 2008b

\section{Conclusions}

Consumer electronics and miscellaneous electric products are two of the most diverse residential energy end uses, and consume a substantial amount of energy. The ENERGY STAR portfolio has expanded significantly over the past decade to target these end uses. While some efforts have resulted in successful savings (monitors, imaging equipment, and television standby power) other efforts have fallen short of realizing their full program potential (TV active power, set-top boxes, and computer power management). Modified approaches to best capture untapped potential include focusing on power management education, promoting ENERGY STAR set-top boxes, and maximizing the potential to reduce on mode display power.

\section{References}

Brown, R., C. Webber, and J. Koomey. 2002. "Status and Future Directions of the ENERGY STAR Program.” Energy--The International Journal 27(5): 505-520.

ICF Consulting. 2003. Energy Star Market Penetration Report Calendar Year 2002. Prepared for the US Environmental Protection Agency, Climate Protection Partnership Division, ENERGY STAR Program. Washington, DC: ICF Consulting. 
. 2004. Energy Star Market Penetration Report Calendar Year 2003. Prepared for the US Environmental Protection Agency, Climate Protection Partnership Division, ENERGY STAR Program. Washington, DC: ICF Consulting.

—. 2006a. Energy Star Unit Shipment Data Report Calendar Year 2004. Prepared for the US Environmental Protection Agency, Climate Protection Partnership Division, ENERGY STAR Program. Washington, DC: ICF Consulting.

- 2006b. Energy Star Unit Shipment Data Report Calendar Year 2005 (Final Draft). Prepared for the US Environmental Protection Agency, Climate Protection Partnership Division, ENERGY STAR Program. Washington, DC: ICF Consulting.

-2007. Energy Star Unit Shipment Data Report Calendar Year 2006 (Final Draft). Prepared for the US Environmental Protection Agency, Climate Protection Partnership Division, ENERGY STAR Program. Washington, DC: ICF Consulting.

McWhinney, M., A. Fanara, R. Clark, C. Hershberg, R. Schmeltz, and J. Roberson. 2005. "Energy Star product specification development framework: using data and analysis to make program decisions.” Energy Policy 33(12): 1613-1625.

Porter, S., L. Moorefield, and P. May-Ostendorp. 2006. Final field research report. Prepared for the California Energy Commission Public Interest Research Program (PIER) by Ecos Consulting under contract 500-04-030. October.

Rosen, K., and A. Meier. 1999. Energy Use of Televisions and Videocassette Recorders in the U.S. LBNL-42393. Berkeley, California: Lawrence Berkeley National Laboratory.

Roth, K., K. McKenney, R. Ponoum, and C. Paetsch. 2007. Residential Miscellaneous Electric Loads: Energy Consumption Characterization and Energy Savings Potential. Prepared for U.S. DOE by Tiax LLC. Boston, Massachusetts: TIAX LLC.

Sanchez, M., R. Brown, C. Webber, and G. Homan. 2008. Savings Estimates for the EPA ENERGY STAR Voluntary Labeling Program. Energy Policy 36(2008): 2098-2108.

Sanchez, M., J. Koomey, M. Moezzi, A. Meier, and W. Huber. 1998. "Miscellaneous electricity in U.S. homes". Energy Policy 26(8): 585-593.

US EPA. 2008a. Masked manufacturer TV power consumption test dataset. Washington, DC: United States Environmental Protection Agency.

- 2008b. Masked manufacturer TV power consumption test dataset. Washington, DC: United States Environmental Protection Agency.

Webber, C., J. Roberson, M. McWhinney, R. Brown, M. Pinckard, and J. Busch. 2006. "Afterhours Power Status of Office Equipment in the USA." Energy. 31(14): 2823-2838. 